\title{
Final Report on Actinide Glass Scintillators for Fast Neutron Detection
}

\section{Bliss}

JA Stave

October 2012

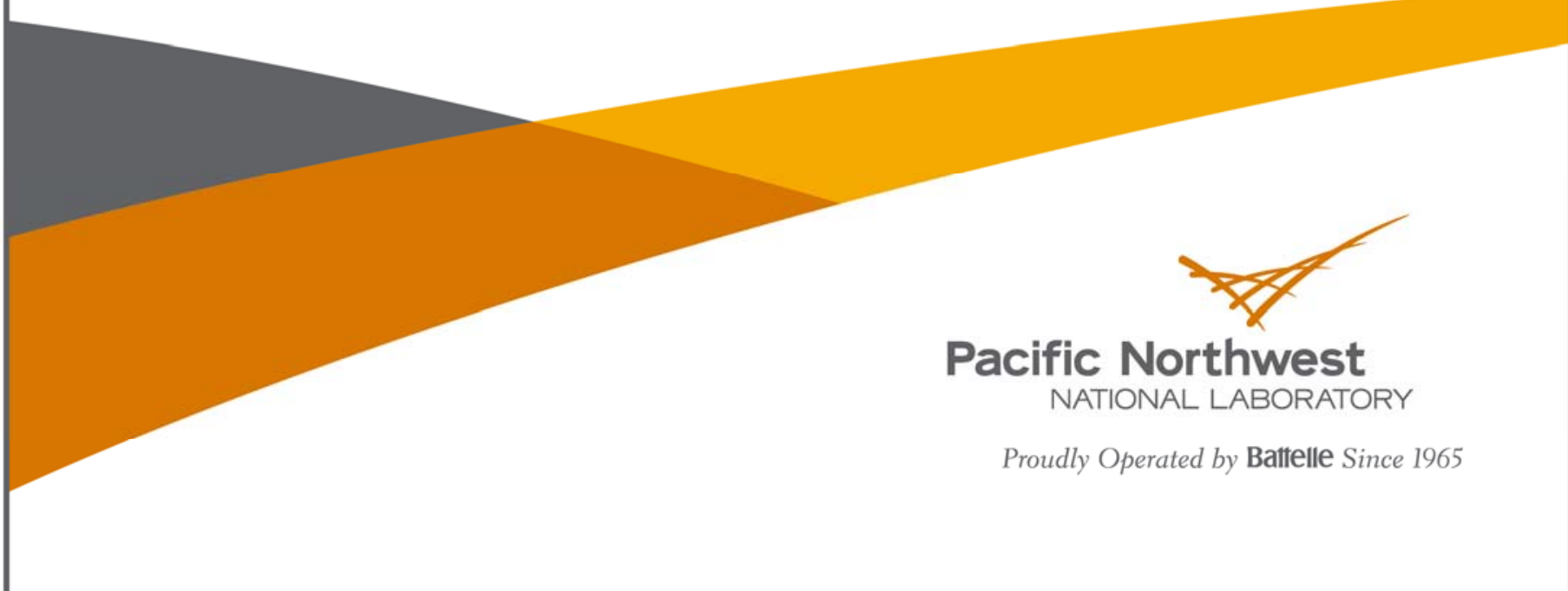




\title{
DISCLAIMER
}

This report was prepared as an account of work sponsored by an agency of the United States Government. Neither the United States Government nor any agency thereof, nor Battelle Memorial Institute, nor any of their employees, makes any warranty, express or implied, or assumes any legal liability or responsibility for the accuracy, completeness, or usefulness of any information, apparatus, product, or process disclosed, or represents that its use would not infringe privately owned rights. Reference herein to any specific commercial product, process, or service by trade name, trademark, manufacturer, or otherwise does not necessarily constitute or imply its endorsement, recommendation, or favoring by the United States Government or any agency thereof, or Battelle Memorial Institute. The views and opinions of authors expressed herein do not necessarily state or reflect those of the United States Government or any agency thereof.

\author{
PACIFIC NORTHWEST NATIONAL LABORATORY \\ operated by \\ BATTELLE \\ for the \\ UNITED STATES DEPARTMENT OF ENERGY \\ under Contract DE-AC05-76RL01830
}

Printed in the United States of America
Available to DOE and DOE contractors from the Office of Scientific and Technical Information, P.O. Box 62, Oak Ridge, TN 37831-0062; ph: (865) 576-8401 fax: $(865) 576-5728$
email: reports@adonis.osti.gov
Available to the public from the National Technical Information Service 5301 Shawnee Rd., Alexandria, VA 22312 ph: (800) 553-NTIS (6847) email: orders $a$ ntis.gov $<$ http://www.ntis.gov/about/form.aspx> Online ordering: http://www.ntis.gov




\section{Final Report on Actinide Glass Scintillators for Fast Neutron Detection}

M Bliss

JA Stave

October 2012

Prepared for

the U.S. Department of Energy

under Contract DE-AC05-76RL01830

Pacific Northwest National Laboratory

Richland, Washington 99352 

PNNL-21976

\section{Summary}

This is the final report of an experimental investigation of actinide glass scintillators for fast-neutron detection. It covers work performed during FY2012. This supplements a previous report, PNNL-20854 "Initial Characterization of Thorium-loaded Glasses for Fast Neutron Detection" (October 2011). The work in FY2012 was done with funding remaining from FY2011. As noted in PNNL-20854, the glasses tested prior to July 2011 were erroneously identified as scintillators. The decision was then made to start from "scratch" with a literature survey and some test melts with a non-radioactive glass composition that could later be fabricated with select actinides, most likely thorium. The normal stand-in for thorium in radioactive waste glasses is cerium in the same oxidation state. Since cerium in the $3+$ state is used as the light emitter in many scintillating glasses, the next most common substitute was used: hafnium. Three hafnium glasses were melted. Two melts were colored amber and a third was clear. It barely scintillated when exposed to alpha particles.

The uses and applications for a scintillating fast neutron detector are important enough that the search for such a material should not be totally abandoned. This current effort focused on actinides that have very high neutron capture energy releases but low neutron capture cross sections. This results in very long counting times and poor signal to noise when working with sealed sources. These materials are best for high flux applications and access to neutron generators or reactors would enable better test scenarios. The total energy of the neutron capture reaction is not the only factor to focus on in isotope selection. Many neutron capture reactions result in energetic gamma rays that require large volumes or high densities to detect. If the scintillator is to separate neutrons from gamma rays, the capture reactions should produce heavy particles and few gamma rays. This would improve the detection of a signal for fast neutron capture. 

PNNL-21976

\title{
Acronyms and Abbreviations
}

\author{
DOE \\ U.S. Department of Energy \\ HPGe \\ High-purity germanium detector \\ MCNP \\ Monte Carlo N-Particle Transport Code \\ NA-22 \\ Office of Nonproliferation and Verification Research and Development \\ NNSA \\ National Nuclear Security Administration \\ PMT \\ Photomultiplier Tube \\ PNNL \\ Pacific Northwest National Laboratory
}



PNNL-21976

\section{Contents}



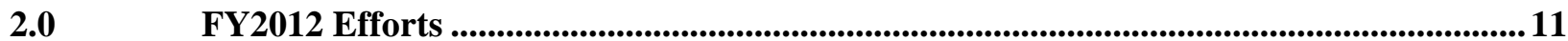

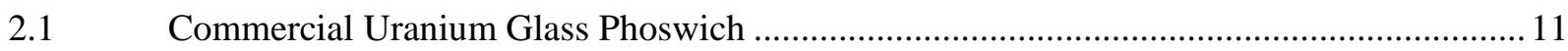

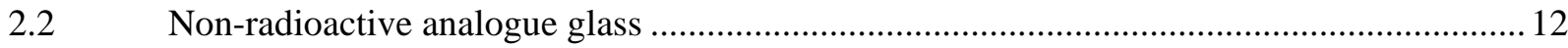

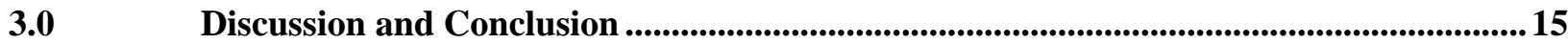

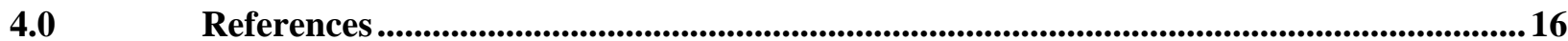


PNNL-21976

\section{Figures}

Figure 1: Commercial uranium glass compared to enriched lithium glass. The blue curve is the thermal neutron response of enriched lithium glass alone, exposed to moderated ${ }^{252} \mathrm{Cf}$. The other curves represent responses captured with the uranium glass mounted on the enriched lithium glass. The uranium glass reduced the thermal neutron response of the enriched

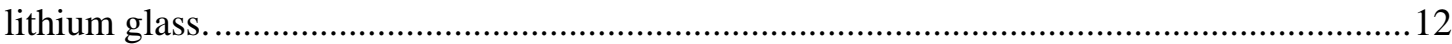

Figure 2: Ten-hour background and AmBe counting runs of the clear hafnium-loaded glass .......14 
PNNL-21976

\section{Tables}

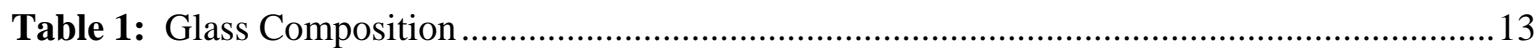


PNNL-21976

\subsection{Introduction}

The United States Department of Energy (DOE) National Nuclear Security Administration's (NNSA) Office of Nonproliferation and Verification Research and Development (NA-22) has sponsored a research effort by Pacific Northwest National Laboratory (PNNL) to investigate actinide-loaded glasses as fastneutron detectors. This report presents glass-doping results for the second year of the project, fiscal year 2012. The majority of the work was performed during the first two quarters of the fiscal year with carryover funds from FY2011. In July of FY2011, it was realized that past experiments identified glasses as scintillators when they were indeed not. Data from this and a previous project were discarded and recollected. None of the samples on hand scintillated even in response to alpha particles (Bliss 2011). The decision was made to work with non-radioactive analogue glasses. Controlled atmosphere melting that is key to oxidation-state control of the activator is readily available for non-radioactive glasses. If a scintillating analogue glass could be developed, then the process could be modified for melts with actinides in the Radiochemical Processing Laboratory at PNNL.

The original premise of this work was to detect fast-neutron capture by actinides within a scintillating glass matrix. Neutron capture and subsequent fission releases very high energies of $\sim 200 \mathrm{MeV}$ for ${ }^{232} \mathrm{Th}$, ${ }^{238} \mathrm{U}$, and ${ }^{237} \mathrm{~Np}$. This project is based primarily on ${ }^{232} \mathrm{Th}$ because of its commercial availability, known glass forming behavior and high natural isotopic abundance. The initial driver for this research is to produce an alternative to fission chambers. Fission chambers are not readily available commercially and are custom fabricated, requiring long lead times. There are also other applications for a solid-state fastneutron detector. Nuclear reactor burn-up and spent-fuel monitoring are of primary concern; and commercially, petroleum-well monitoring would benefit from a robust fast-neutron detector.

This report covers data and samples from FY2012 not included in the previous report (Bliss 2011). The data in this report was collected using procedures and electronics described in that report. 
PNNL-21976

\subsection{FY2012 Efforts}

\subsection{Commercial Uranium Glass Phoswich}

Many of the actinides emit high-energy gamma rays and particles in response to neutron capture. The previous LDRD project investigated the possibility of using commercial uranium glass as a scintillator. Uranium glass is available commercially from Kopp Glass (Pittsburgh, PA). The vendor was willing to disclose the nominal uranium oxide content, fluorescence behavior and boron content of their standard filter glasses. ${ }^{1}$ Based on this communication we ordered a glass that contained $0.49 \mathrm{wt} . \% \mathrm{UO}_{2}$, no boron, and fluoresced. Although low in uranium content, use of a commercial glass for the basis of a detector would be fast and convenient. Commercial uranium glass was found not to scintillate intrinsically (by the previous LDRD project). For the current project, another known scintillator (enriched lithium glass) was placed in contact with commercial uranium glass to detect any resultant particles or photons originating from uranium neutron captures. The enriched-lithium glass was used because several 3-cm disks were readily available.

The commercial uranium-loaded glass (Kopp filter glass \#3718) was mounted on the PNNL-developed enriched lithium glass and exposed to the mixed gamma and neutron flux from ${ }^{252} \mathrm{Cf}$. The response of the paired glasses was compared to the response of the lithium glass alone. The lithium glass alone showed the thermal neutron capture peak at channel $1500(\sim 1.9 \mathrm{MeV})$. No significant response was observed when the uranium glass was mounted on to the lithium glass. The uranium glass did appear to filter out thermal neutrons from reaching the lithium glass, but no new signal related to neutron capture was observed.

\footnotetext{
${ }^{1}$ Email from Hugh Reed of Kopp Glass dated December, 12, 2009.
} 
PNNL-21976

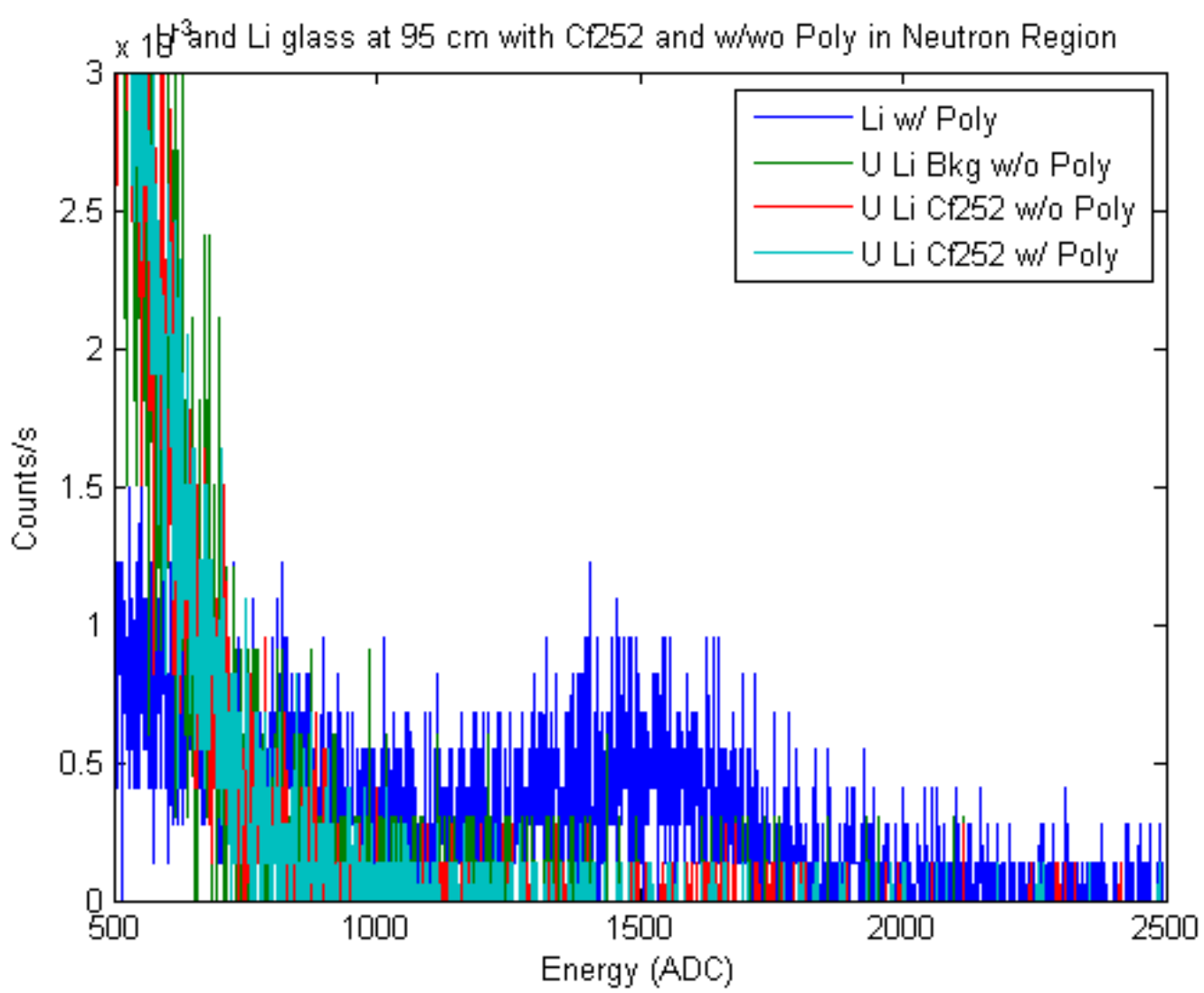

Figure 1: Commercial uranium glass compared to enriched lithium glass. The blue curve is the thermal neutron response of enriched lithium glass alone, exposed to moderated ${ }^{252} \mathrm{Cf}$. The other curves represent responses captured with the uranium glass mounted on the enriched lithium glass. The uranium glass reduced the thermal neutron response of the enriched lithium glass.

\subsection{Non-radioactive analogue glass}

The realization that none of the thorium loaded glasses on hand scintillated indicated that a composition study would be necessary. Also, past efforts in scintillating glasses indicated that scintillation was more probable when the rare-earth activators were in reduced oxidation states. Specifically, cerium needs to be in the $3+$ oxidation state and europium needs to be in the 2+ state to scintillate. A literature survey was performed to identify a viable stand-in for thorium in the glasses. The substitute element needed to have similar oxidation states and comparable ionic size. The most common substitute for thorium in radioactive waste glass development is cerium. Cerium is also an activator for scintillation and would interact with other rare-earth activators. As an activator, cerium needs to be in the $3+$ oxidation state; this is not the normal state for thorium, which is normally 4+ in glasses. An alternative candidate is lead. However, lead has safety issues in glass melting and is easily reduced to the metal. It is not suitable for melting in reducing atmospheres to test various activator oxidation states for scintillation. The next closest replacement for thorium is hafnium. Replacing thorium in the base glass composition would allow glass melts in reducing and oxidizing atmospheres to control the light emitting activators. If reducing atmospheres are necessary to produce scintillation light, then a chemical method would be 
needed to keep the melt reduced. This method would be developed using the analogue glass, and then transferred to a thorium or other actinide-loaded glass. A standard method for reducing glasses is to add carbon or organic compounds that rapidly react with oxygen, creating an oxygen-deficient atmosphere in the crucible or furnace. These reactions can be difficult to control, but this approach can work with existing radioactive glass processing equipment and facilities at PNNL.

Three sources of hafnium were selected: $\mathrm{Hf}\left(\mathrm{SO}_{4}\right)_{2}, \mathrm{HfCl}_{2} \mathrm{O} \bullet 8 \mathrm{H}_{2} \mathrm{O}$ and $\mathrm{Hf}\left(\mathrm{NO}_{3}\right)_{2} \mathrm{O} \cdot 2 \mathrm{H}_{2} \mathrm{O}$. The base glass composition was the "lower Z" variant of the thorium-loaded glass produced previously with $\mathrm{HfO}_{2}$ replacing $\mathrm{ThO}_{2}$ (Table 1). The boron source was enriched ${ }^{11} \mathrm{~B}$ to minimize thermal neutron interactions. Cerium was used as the activator to generate scintillation light. Cerium was tried first as a melting process for keeping cerium in the reduced oxidation state is already well established in our laboratory. This process uses induction heating and a glass enclosure vented to a chemical hood system. Platinum crucibles were used and a reducing gas mix is bubbled into the molten glass to control the oxidation state and mix the glass. Samples were poured in air onto heated steel plates and annealed in air. Each melt was measured to produce $50 \mathrm{~g}$ of glass, of which a fraction could be poured from the crucible. The remaining glass in the crucible was quenched and stored, but not used for measurements.

All three sources of hafnium produced glass. The $\mathrm{Hf}\left(\mathrm{SO}_{4}\right)_{2}$ and $\mathrm{HfCl}_{2} \mathrm{O} \bullet 8 \mathrm{H}_{2} \mathrm{O}$ produced amber colored glasses. The $\mathrm{Hf}\left(\mathrm{SO}_{4}\right)_{2}$ melt formed a black residue on the platinum crucible and lid that could only be removed by heating in air. Iron sulfur ligands in silicate glass produce the brown color typical in beer bottles, so at the time, the amber color was attributed to residual sulfur in the glass. However, the next melt using $\mathrm{HfCl}_{2} \mathrm{O} \cdot 8 \mathrm{H}_{2} \mathrm{O}$ as the source of $\mathrm{HfO}_{2}$ also produced amber colored glass. Cerium in the 4+ state produces a pale brown color in the PNNL enriched-lithium glass; the amber color in the hafniumloaded glasses may be caused by cerium in the 4+ state, but the value of the color was much deeper than in the lithium glasses. The hue caused by a given cation can vary depending on the band gap of the host glass or the formation of ligands with ions other than oxygen. More importantly, these glasses did not appear to fluoresce, nor did they scintillate when exposed to alpha particles, gamma rays or neutrons.

Table 1: Glass Composition

\begin{tabular}{||c|c||}
\hline Oxide & Mole \% \\
\hline \hline $\mathrm{SiO}_{2}$ & 45.9 \\
\hline $\mathrm{B}_{2} \mathrm{O}_{3}$ & 26.0 \\
\hline $\mathrm{Na}_{2} \mathrm{O}$ & 13.9 \\
\hline $\mathrm{CaO}$ & 3.7 \\
\hline $\mathrm{MgO}$ & 7.5 \\
\hline $\mathrm{HfO}_{2}$ & 3.0 \\
\hline $\mathrm{Ce}_{2} \mathrm{O}_{3}$ & .05 \\
\hline
\end{tabular}


The production of colored glasses from two different sources of hafnium indicated that although raw materials with the desired oxidation state were batched, our controlled atmosphere melting process was not maintaining those states. To mitigate the problem, all equipment was thoroughly cleaned and inspected. The mass flow controller on the reducing gas mixing system was not delivering the desired flow rates; this was adjusted manually. The next melt used $\mathrm{Hf}\left(\mathrm{NO}_{3}\right)_{2} \mathrm{O} \cdot 2 \mathrm{H}_{2} \mathrm{O}$ as a raw material. Nitrogen is soluble in silicate glasses and can substitute for oxygen. Bubbling nitrogen gas into a silicate glass melt will result in substitution and a characteristic increase in refractive index. Although glass melting includes decomposition reactions and high temperatures, the raw materials can have significant impact on the final glass. This final glass appeared to be amber when poured, but cooled to clear glass in both the poured sample and the quenched glass remaining in the crucible. This glass fluoresced weakly under broadband UV illumination.

Scintillation testing for the final hafnium glass using ${ }^{60} \mathrm{Co}(2.5 \mu \mathrm{Ci})$ gamma rays (mainly 1.17 and $1.33 \mathrm{MeV}$ ), and ${ }^{137} \mathrm{Cs}(1 \mu \mathrm{Ci})(662 \mathrm{keV})$ were inconclusive for moderate counting times of up to two hours. Hafnium does undergo a neutron capture reaction that produces several high-energy gamma rays, so there is a possibility that hafnium-loaded glasses would respond to fast neutrons. Figure 2 shows a tenhour exposure to a lead-shielded AmBe source with a ten-hour background for comparison. The overall signal increased in the presence of the AmBe source, but no new features appear in the pulse-height spectrum. If neutron capture events are causing the signal to increase above background, the response is not creating a distinct signal for neutron capture. The sample is too small to stop the few high energy gamma rays that would be expect from hafnium capture. Further measurements with a secondary detector would be needed to fully understand the response to neutrons.

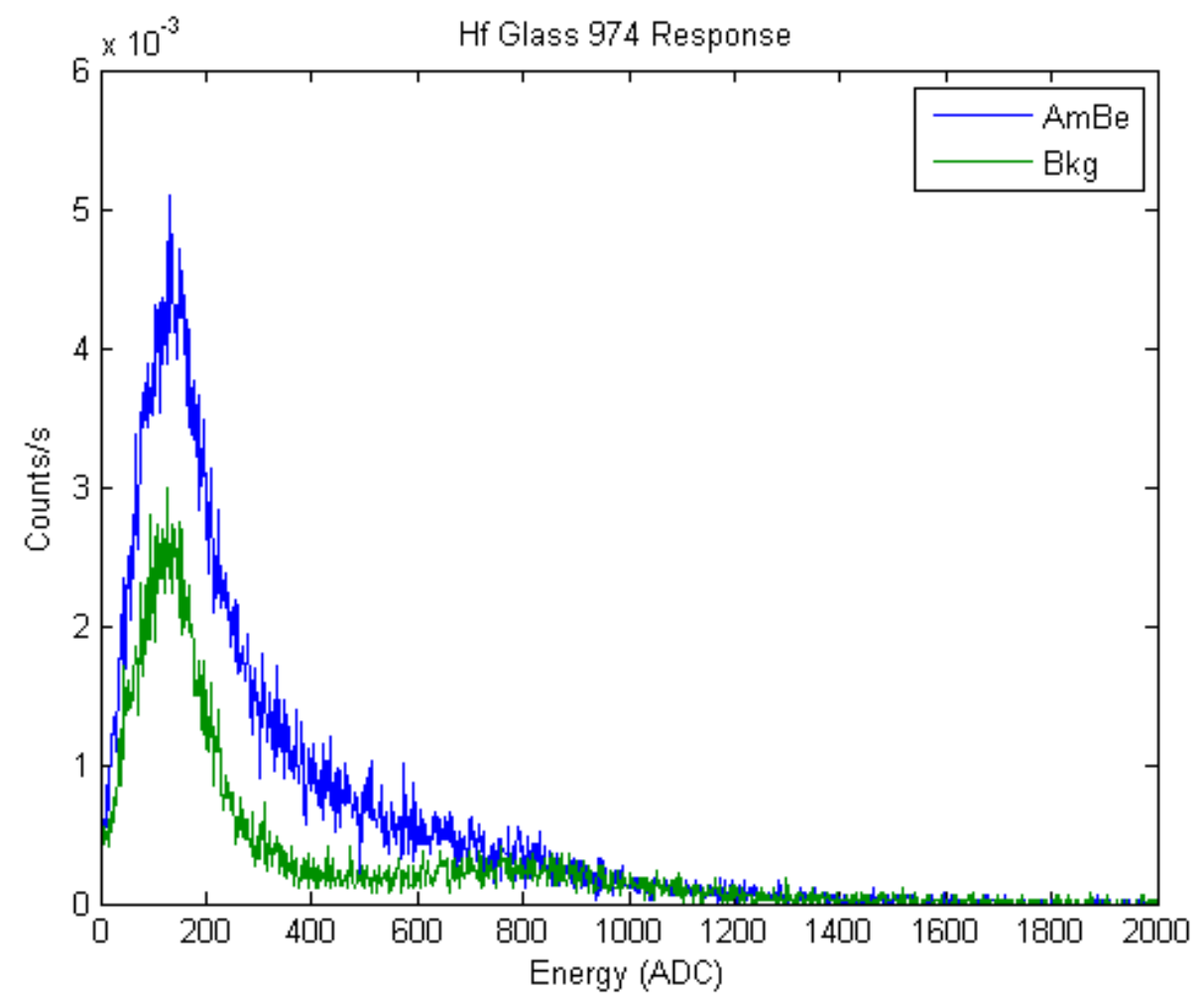

Figure 2: Ten-hour background and AmBe counting runs of the clear hafnium-loaded glass 


\subsection{Discussion and Conclusion}

None of the glasses in this study produced significant scintillation or indicated a significant response to fast neutrons. The effort, however, did not fully explore or exhaust the possible parameter space for glasses that scintillate in response to fast neutrons. For example, cerium produces the fastest signals as an activator in glasses, but it also emits the smallest signal. Other rare earths produce many more photons per event, generally at longer wavelengths and with longer decay times. Cerium is also more sensitive to the UV edge of the glass matrix and may not be the best choice for an activator for this particular glass system. Other brighter rare earths should be tried. Terbium and erbium are frequently used in scintillating glasses and generally produce more photons at longer wavelengths. They are much less sensitive to the UV edge of the glass matrix.

In retrospect, it would have been more prudent to start with well-established scintillating glass compositions and test their responses to neutron capture materials as coatings or dopants. A key issue with the selection of the neutron-capture nucleus is not only the energy of the reaction, but the byproducts. A capture reaction that produces gamma rays may not be separable from other gamma ray sources. The alpha and triton from ${ }^{6} \mathrm{Li}$ capture travel tens of microns through silicate glasses. This long track may be necessary to minimize recombination of excited states before a distinct optical signal can be produced. Even the best performing enriched lithium glasses have finite tailing of gamma rays into the neutron capture regime. The ultimate issue is detection efficiency. Nuclei with very high capture cross sections and energetic capture reactions are needed at high loadings for most practical measurements. Radioactive isotopes are not a good starting point for an effort to develop an inorganic scintillator for fast neutrons. Future efforts in this area need to put more effort into neutron capture element selection along with some preliminary GEANT and/or MCNP models to predict neutron capture rates so that bench scale experiments can be designed. Potential applications would be limited to situations with very high neutron fluxes, such as spent fuel monitoring and nuclear reactors. 
PNNL-21976

\subsection{References}

Bliss, M, JA Stave, Z Wang, JW Hayes, and MJ Schweiger. 2011. "Initial Characterization of Thoriumloaded Glasses for Fast Neutron Detection." PNNL-20854. Pacific Northwest National Laboratory, Richland, WA. 


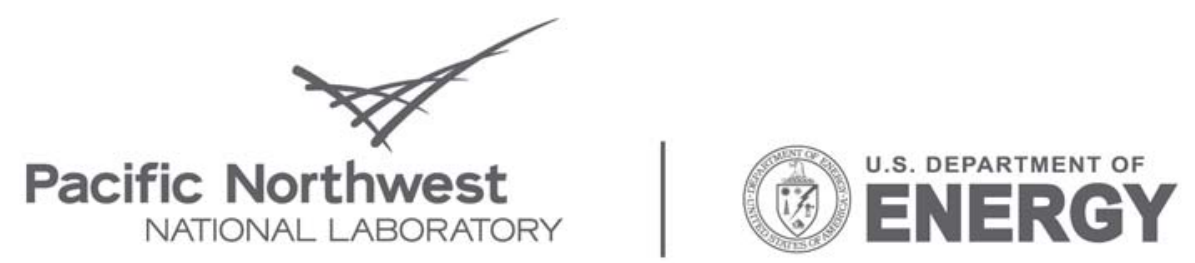

Proudly Operated by Battelle Since 1965

902 Battelle Boulevard

P.O. Box 999

Richland, WA 99352

1-888-375-PNNL (7665)

www.pnl.gov 